\title{
Neurobehavioral outcomes in patients with myelomeningocele
}

\author{
Sophie Foss, PhD, ${ }^{1}$ Tracy M. Flanders, MD, ${ }^{2}$ Gregory G. Heuer, MD, PhD, ${ }^{2,3}$ and \\ Jane E. Schreiber, $\mathrm{PhD}^{1,3}$ \\ 1Department of Child and Adolescent Psychiatry and Behavioral Sciences, and Divisions of ${ }^{2}$ Neurosurgery and ${ }^{3}$ Pediatric \\ General, Thoracic and Fetal Surgery, Children's Hospital of Philadelphia, Pennsylvania
}

\begin{abstract}
This paper describes some of the more common patterns in neurobehavioral deficits and their underlying neuroanatomical basis in myelomeningocele (MMC). Patients with MMC can face a lifetime of specific organ system dysfunction, chief among them spinal cord malformations, orthopedic issues, hydrocephalus, and urological disabilities. In addition, patients can experience specific patterns of neurobehavioral difficulties due to the changes in neuroanatomy associated with the open spinal defect. Although there is variability in these patterns, some trends have been described among MMC patients. It is thought that early recognition of these potential neurobehavioral deficits by treating neurosurgeons and other members of the treatment team could lead to earlier intervention and positively impact the overall outcome for patients. Neurodevelopmental and neurobehavioral follow-up assessments are recommended to help guide planning for relevant treatments or accommodations.
\end{abstract}

https://thejns.org/doi/abs/10.3171/2019.7.FOCUS19445

KEYWORDS myelomeningocele; neurobehavioral outcomes; hydrocephalus; Chiari II malformation

$\mathrm{S}$ PINA bifida is a congenital malformation in which the neural tube fails to develop and close properly, resulting in a defect in early neurulation. ${ }^{17}$ Open spina bifida, or myelomeningocele (MMC), is the most common and severe form of spina bifida. Due to altered neurodevelopment, individuals with MMC often have multiple central nervous system (CNS) abnormalities that include the spinal cord and multiple brain regions. ${ }^{17}$ We aim to describe these CNS abnormalities and discuss the range of possible neurobehavioral outcomes that can occur in individuals with MMC. These patterns should be recognized by the treatment team, including the neurosurgeon, so as to positively impact patient outcome and identify patients who may be experiencing a decline related to reversible neurosurgical disease.

\section{Anatomical Basis for Neurobehavioral Changes}

MMC affects multiple anatomical levels, causing abnormalities in the spinal cord, cerebellum, brainstem, corpus callosum, and cerebral ventricles (Fig. 1).

\section{Spinal Cord Lesion}

Individuals with MMC typically exhibit sensory and motor deficits below the level of the spinal lesion. The lesion can occur at different levels, with greater impacts on functional outcome associated with lesions located at higher spinal levels. ${ }^{5,30}$ Patients experience a range of deficits, including lower-limb weakness or paralysis, sensory loss, incontinence, and musculoskeletal anomalies. Thoracic-level lesions are associated with more severe brain abnormalities, which are in turn associated with worse neurobehavioral outcomes. ${ }^{20,30}$ Motor impairments may alter the developmental trajectory from birth because movement restrictions limit environmental exploration and learning experiences..$^{50}$

\section{Chiari II Malformation}

Chiari II malformation (CM-II) consists of several structural changes, most significantly deformity of the brainstem and cerebellum. Approximately $96 \%$ and $90 \%$ of children with spinal lesions at T12 or higher and below T12 meet criteria for CM-II, respectively. ${ }^{30}$ The CM-II unified theory ${ }^{54}$ posits that a cascade of interrelated, time-

ABBREVIATIONS CC = corpus callosum; CM-II = Chiari II malformation; CNS = central nervous system; MMC = myelomeningocele; SES = socioeconomic status. SUBMITTED May 31, 2019. ACCEPTED July 25, 2019.

INCLUDE WHEN CITING DOI: 10.3171/2019.7.FOCUS19445. 


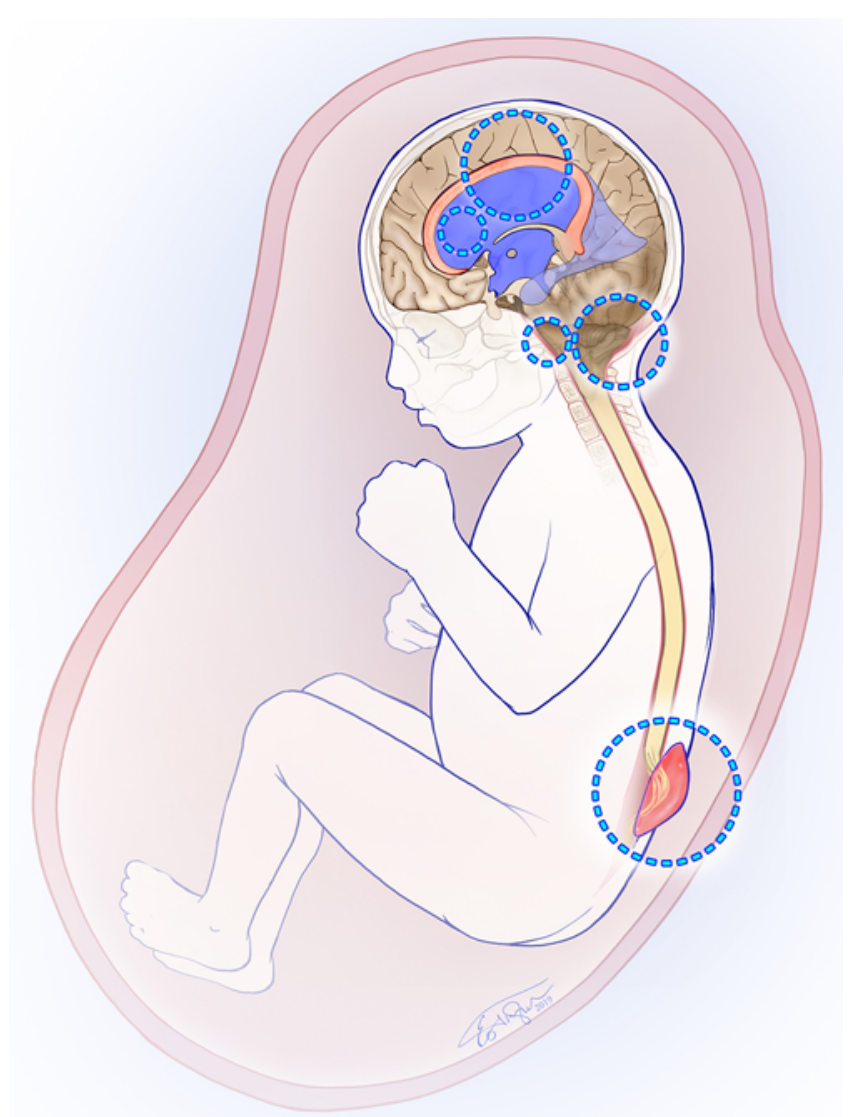

FIG. 1. An MMC exposes the spinal cord to the deleterious effects of amniotic fluid on the neural placode, which results in neurological compromise and injury (lower blue circle). The egress of CSF via the spinal defect is thought to adversely affect the brainstem and cerebellum (middle blue circles) and result in tectal beaking and cerebellar tonsil herniation. The downward herniation of the infratentorial brain structures promotes obstruction in the cerebral aqueduct and fourth ventricle, which results in enlargement of the lateral and third ventricles (upper blue circles). Ventriculomegaly and, subsequently, clinical hydrocephalus develop and stretch the periventricular cortex. Copyright Stream Studios at Children's Hospital of Philadelphia. Artist Eo Trueblood. Published with permission.

dependent defects unfolds during embryonic and fetal development, resulting in pathophysiology. Leakage of CSF through the spinal defect prevents normal distention of the embryonic ventricular system, limiting growth of the posterior fossa. ${ }^{54}$ The cerebellum develops in a smaller posterior fossa, resulting in displacement of the cerebellar tonsils, vermis, and brainstem through the foramen magnum into the spinal canal. Consequently, abnormalities may occur in other cerebral areas as well, including corpus callosum (CC) hypoplasia, tectal beaking, polymicrogyria, and cortical heterotopias. ${ }^{53}$ Thus, CM-II can lead to a constellation of brain abnormalities that impact neurodevelopment and compromise aspects of neurobehavioral functioning.

\section{Cerebellum}

The cerebellum has long been considered important for the timing and coordination of movement. Damage to the cerebellum generally leads to difficulties with motor control, including truncal and axial movements..$^{55}$ More recently, the cerebellum has emerged as critical in cognition as well, particularly executive functioning, due to corticocerebellar pathways. ${ }^{68}$ Individuals with MMC typically have a reduced cerebellar volume, ${ }^{65}$ with further reductions seen with higher-level lesions. ${ }^{20}$ Cerebellar reorganization also results in a larger anterior portion and smaller posterior-inferior region. ${ }^{44}$ While the anterior lobe of the cerebellum is generally associated with motor function, individuals with MMC often show deficits in the timing and precision of truncal, upper-limb, and eye movements. ${ }^{24}$

\section{Brainstem and Midbrain}

Brainstem and midbrain structures can develop abnormally due to overcrowding in the small posterior fossa and herniation of hindbrain structures through the foramen magnum. Approximately $65 \%$ of individuals with MMC have distortion of the midbrain, often marked by tectal beaking in which the colliculi fuse into a single beak. ${ }^{6}$ The medulla is elongated and kinked at the spinomedullary junction in approximately $70 \%$ of patients. ${ }^{6}$ Cerebellar and midbrain structures are both involved in control of eye movements, ${ }^{24,62}$ which tend to be impaired in individuals with MMC. ${ }^{65}$ Abnormalities in the midbrain and tectum are often associated with impairment in attention orienting as well. $14,18,19$

\section{Corpus Callosum}

The CC is the largest subcortical white matter tract involved in interhemispheric transfer and integration of information from one or both hemispheres. ${ }^{49}$ Abnormalities of the CC are seen in approximately $70 \%-90 \%$ of individuals with CM-II and usually consist of hypoplasia or hypogenesis. ${ }^{6}$ The $\mathrm{CC}$ has four subdivisions: rostrum, genu, body, and splenium. ${ }^{63}$ In MMC, CC abnormalities primarily occur in the dorsal part (i.e., splenium), whereas the anterior parts tend to be intact ${ }^{56}$ However, significant variability has been observed in the spectrum of $\mathrm{CC}$ abnormalities in MMC, which include a combination of congenital and acquired (from complications like hydrocephalus) effects on cerebral white matter. ${ }^{35,56}$ Individuals with MMC demonstrate deficits on cognitive tasks requiring recruitment of posterior networks and interhemispheric transfer of information, and severity of impairment is partially dependent on the integrity of the CC..$^{23,35}$

\section{Hydrocephalus}

Hydrocephalus is often conceptualized as a secondary CNS insult related to the CM-II in MMC. It may be caused by aqueductal occlusion, obstruction of the fourth ventricle, or eradication of the subarachnoid space by the overcrowded posterior fossa. Hydrocephalus occurs in approximately $85 \%-90 \%$ of individuals with MMC without fetal neurosurgical intervention. ${ }^{57}$ Expansion of the ventricles typically occurs in a posterior-to-anterior direction and can result in the stretching of parietal and occipital lobe axons around the dilated posterior horns of the lateral ventricles. ${ }^{6}$ Hydrocephalus is often treated with shunt 
placement or endoscopic third ventriculostomy. Unfortunately, shunts can become infected or blocked, and hydrocephalus can recur. Individuals with shunts may require multiple surgical revisions, placing them at risk for continued cerebral damage and infection. Children with MMC and either arrested hydrocephalus (no shunt) or shunted hydrocephalus tend to exhibit worse neurobehavioral outcomes than children with MMC who do not have hydrocephalus..$^{5,34}$

\section{Other Regions of the Cerebrum}

Additional cerebral abnormalities can occur in MMC but are much less common. Gray matter heterotopias occur in about $19 \%$ of MMC cases. ${ }^{56}$ Seizures occur in approximately $15 \%-25 \%$ of MMC patients and are likely related to heterotopias and polymicrogyria. ${ }^{11,15}$ Seizures and additional brain abnormalities have added deleterious effects on neurobehavioral outcomes.

\section{Neurobehavioral Profile of MMC}

As the result of these neurological and medical sequelae, children with MMC are at increased risk of neurobehavioral difficulties. A pattern of specific neurobehavioral challenges constitutes a "characteristic" profile often seen in MMC; that said, cognitive difficulties can be significantly impacted by environmental, psychosocial, and demographic factors, including medical/developmental interventions, family socioeconomic status (SES), and race/ ethnicity, which leads to individual variability in specific difficulties. Existing research about neurocognitive profiles in MMC has led to the development of a model of information processing and cognitive phenotypes to explain this variability. ${ }^{23}$ Briefly, this model describes two modes of processing: assembled processing and associative processing. Assembled processing refers to integration of information into larger unified concepts, while associative processing refers to the grouping or categorization of information..$^{23}$ Assembled processing is typically thought to be negatively affected by the underlying neuropathophysiology and associated core deficits of MMC. In contrast, associative processing is typically less affected by the underlying neurophysiological changes of MMC but is more vulnerable to differences in the environment, like family SES and education. For a more detailed discussion of this model, see an overview written by Fletcher and Dennis. ${ }^{31}$ The following sections describe how differential strengths and weaknesses in assembled and associative processing tend to manifest in each neurobehavioral domain.

\section{Intelligence}

Individuals with MMC generally have slightly lower IQs than those of the general population, though the presence of complications affects outcomes. Individuals with MMC without hydrocephalus have an IQ about one-half a standard deviation below the mean but still remain within the average range. ${ }^{34,52}$ The presence of hydrocephalus is associated with a decrease of about 1 full standard deviation, leading to mean scores in the low-average range. ${ }^{34,52}$ Shunt-related complications can further negatively impact IQ, as well. ${ }^{3,4}$ Children with MMC also tend to show rela- tively stronger verbal reasoning and relatively weaker nonverbal reasoning..$^{23,34}$

\section{Attention}

Attention is generally conceptualized as a 3-part system, with distinct networks guiding 3 key aspects: alerting, orienting, and executive control. ${ }^{59}$ This system is divided into anterior and posterior networks, which control alerting and sustained attention, and attention orientation, respectively. While these systems certainly overlap in dayto-day attention, children with MMC generally have more difficulty with orienting attention and shifting focus, likely due to structural and functional abnormalities in brain regions involved in the posterior attention system. They show slowed orientation to both internal and external cues and take longer to reorient their attention to an area they have already attended to (also known as inhibition of return) as compared with healthy controls. ${ }^{18,19}$ In contrast, sustained attention is usually fairly age appropriate in MMC,$^{13}$ which is thought to reflect a more typical anterior attention system. ${ }^{51}$

\section{Executive Functions}

Executive functions are a broad group of cognitive skills that help an individual work toward complex goals, including initiation, inhibition, sequencing, fluency, planning, integration, and organization. ${ }^{26}$ While frontal lobe networks have long been implicated in executive functions, cerebellum and corticocerebellar pathways also play a role. ${ }^{68}$ In MMC, altered cerebellar structure affects several aspects of executive functions, including timing, sequencing of information, and organization, ${ }^{23}$ with executive function deficits persisting in individuals with MMC even when IQ is controlled for. ${ }^{14,64}$ Some aspects of executive function difficulty, such as speed and integration of context to understand metaphors, are thought to be associated with $\mathrm{CC}$ dysgenesis. ${ }^{43}$

\section{Language}

Language is often hailed as a strength for children with MMC. In the aspects of language involving more concrete knowledge, such as grammar and lexicon, individuals with MMC generally show age-appropriate performance. ${ }^{28}$ However, they often struggle more with higher-level tasks, such as understanding others' meaning, using language in context, and speaking in a complex manner., These difficulties tend to appear in both spoken and written language.

\section{Memory}

Explicit memory refers to intentional recollection of prior experiences or previously learned information, while implicit memory is the use of learned information without conscious awareness. Prospective memory is the concept of remembering to do something in the future (such as doing a task at a specific time). Sometimes categorized as part of executive function, working memory is a system that holds information in mind for immediate processing. These specific learning and memory functions appear to be differentially impacted in MMC, such that individu- 
als with MMC often have strengths in rote memorization and show fairly typical implicit memory ${ }^{23,75}$ but have more difficulty with explicit and prospective memory, which is thought to be due to the disrupted development of subcortical structures and associated networks. ${ }^{22,71,75}$ Individuals with MMC also struggle to use previously learned information flexibly or in novel ways because of their executive function difficulties. Furthermore, these patients show difficulties with reconstructive memory as opposed to recognition or repetition. ${ }^{22,23}$ Working memory appears to generally be adequate with simple information but decreases with complex demands. ${ }^{22}$

\section{Visuospatial Functions}

Children with MMC often show weaknesses in visuospatial functions, including perception, construction, and analysis. ${ }^{21}$ Many of the structural and functional changes that occur in neurodevelopment with MMC affect the posterior portion of the brain, where many networks involved in visual function are based. ${ }^{74}$ Hydrocephalus also tends to exert greater impact on posterior brain regions. ${ }^{6}$ Furthermore, the cerebellum is important for aspects of visuospatial functions, including timing and sequencing of information. Weaker visuospatial skills in MMC may also be related to the transfer and integration of information between visual areas of both hemispheres via the CC. ${ }^{29,37}$

\section{Motor Functions}

Children with MMC have impaired movement and motor functions. ${ }^{20}$ These difficulties are thought to arise from physiological changes to the cerebellum and midbrain, as well as spinal lesion level. ${ }^{24}$ Although individuals with MMC typically retain the ability to learn motoric tasks, they have much more difficulty with precise timing and the smoothness of motor functions, resulting in imprecise and arrhythmic movements often manifesting as dysmetria, ataxia, or dysarthria. ${ }^{20,24}$ The combined motor and visuospatial deficits in MMC can lead to difficulties with real-world tasks such as handwriting and drawing. ${ }^{72}$

\section{Academic Functions}

Children with MMC have an increased risk of learning and academic difficulties, which can in turn yield negative psychological and occupational outcomes. They generally decode adequately and read fluently, but they struggle to understand the meaning of passages and stories. ${ }^{9}$ Similarly, they can memorize math facts appropriately but struggle to apply numeric knowledge conceptually and use the information flexibly. ${ }^{27}$ In both instances, children can perform in an age-appropriate manner on basic assessments (spelling/math worksheets) but may struggle with real-world tasks or schoolwork involving concepts and flexibility. ${ }^{23,46}$

\section{Psychosocial and Adaptive Concerns}

Individuals with MMC show increased risk of psychological difficulties, including both internalizing (e.g., depression, anxiety) and externalizing (e.g., impulsive behavior) symptoms. ${ }^{46,60,61}$ They also exhibit social difficulties, including decreased acceptability by peers and so- cial competence, and lower-quality friendships. ${ }^{25,42,48}$ The social difficulties are thought to arise both from underlying neurocognitive difficulties and awareness of overt differences from typically developing peers. Furthermore, adaptive functioning outcomes are an important metric of independence and quality of life. Both the individual's specific pathophysiology and aspects of their environment affect adaptive outcomes. Lesion level and severity of motor deficits, as well as higher number of treatments needed in cases with hydrocephalus, significantly impact adaptive and occupational functioning. ${ }^{38}$ Additionally, parents of children with MMC have been found to show higher levels of intrusiveness, psychological control, and authoritarianstyle parenting, ${ }^{40,66}$ which are associated with lower decision-making autonomy in the child and more behavioral concerns. ${ }^{41,66}$ The cognitive difficulties common in MMC can also impact adaptive functioning. In particular, poorer executive functions, like planning and cognitive flexibility, have been linked to decreased adaptive functioning. ${ }^{33,46}$

\section{Variability in Presentation}

While the strengths and weaknesses described above are typically what are seen in MMC, presentation varies significantly due to variability in physiological and environmental factors. Indeed, most neurobehavioral outcomes tend to be worse in individuals with MMC who develop hydrocephalus than in those who do not. ${ }^{34}$ These differences are thought to result from both the presence of hydrocephalus, which itself is known to significantly affect cognitive functioning, and the underlying physiological changes that lead to hydrocephalus, like posterior fossa crowding, CM-II, and hindbrain herniation. ${ }^{33}$ While hydrocephalus treatment varies by child, with some children needing little to no intervention and others requiring serial shunt placements and revisions, the overall presence of hydrocephalus generally signals more impairment in neurobehavioral functioning. ${ }^{34}$

Additionally, when considering characteristics of the common neurobehavioral profile seen with MMC, it is important to take into account environmental factors that impact function and outcomes. The child and family's race/ethnicity, SES, and family cohesion or conflict have been repeatedly found to influence outcomes. ${ }^{30,39,69}$ These environmental aspects are thought to be associated with outcomes because of the multidirectional nature of how a child and his/her environment influence one another, such that children with specific experiences (e.g., living in a household with limited resources or experiencing increased stress from family conflict) interact with their environments differently, in turn shaping their learning experiences..$^{50}$

\section{Current Neurosurgical Treatments}

The primary treatment for MMC is surgical closure of the spinal lesion. Additional treatments involve medical and surgical management of hydrocephalus, spinal cysts, and tethered cord. While closure of the spinal lesion is most commonly done in the immediate postnatal period, the emergence of new surgical techniques in the last 2 decades now allows for in utero closure in a subset of patients 
meeting specific criteria. ${ }^{1}$ Only a fraction of patients diagnosed with MMC during pregnancy qualify for prenatal surgery, and the majority of patients continue to undergo postnatal treatments. Prenatal closure is associated with improved motor functioning, reversal of hindbrain herniation, and decreased risk for a shunt by 30 months of age as compared with postnatal closure. ${ }^{2}$ Since the majority of research on neurobehavioral outcomes was done with children who underwent postnatal closure, updated studies examining outcomes in children with MMC who underwent prenatal closure are needed. One concern related to prenatal closure is the increased risk of preterm birth, ${ }^{2}$ which can have its own deleterious effects on neurocognitive development. ${ }^{16}$ Ongoing research is examining the efficacy of alternate approaches for in utero closure (i.e., modifications of surgical techniques, fetoscopic methods) in attempts to mitigate this increased risk for preterm birth. ${ }^{12,45}$

Additionally, recent changes in the treatment of hydrocephalus are also likely to impact medical and neurodevelopmental outcomes. Historically, around $80 \%$ of children with postnatal MMC closure have required treatment of hydrocephalus with shunt placement.$^{70}$ However, hydrocephalus treatments have evolved over time such that some neurosurgical centers now tend to avoid shunting as long as possible. ${ }^{31}$ Ongoing research and debate regarding the appropriate threshold for intervention continues with toleration of larger ventricles and use of intracranial pressure and neurobehavioral symptoms as new metrics for determining when to intervene. ${ }^{58}$ An additional change is the increasing use of endoscopic third ventriculostomy with choroid plexus coagulation, which is associated with fewer follow-up procedures when successful, in lieu of a shunt. ${ }^{47,73}$ Furthermore, since prenatal closure is associated with a decreased risk for hydrocephalus compared with postnatal closure, rates of hydrocephalus among all children with MMC will continue to change as more prenatal closures are conducted. Management protocols may continue to shift over time, as well. The implications of larger ventricles present in patients treated with endoscopic third ventriculostomy or in patients who do not require shunting but still have larger ventricles than normal will need to be analyzed in future studies with prospective neurobehavioral evaluation.

Shifts in hydrocephalus management with fewer shunt procedures also impact psychosocial outcomes for patients and families. In addition to lower infection and complication risks, families have fewer medical appointments, as well as decreased stress and overall burden, all of which can affect neurodevelopment and child coping. ${ }^{32}$ Since changes in hydrocephalus management have occurred fairly recently, follow-up studies to assess for changes in medical, neurodevelopmental, and psychosocial outcomes in relation to hydrocephalus management are ongoing.

\section{Current Recommendations for Neurodevelopmental Follow-Up}

As part of the healthcare of individuals with MMC, neurodevelopmental and neurobehavioral follow-up is recommended to assess for the presence of motor and cognitive impairments and to help guide planning for inter- ventions or accommodations. The Spina Bifida Association has produced standard-of-care guidelines identifying primary, secondary, and tertiary outcomes to be assessed at specific ages. ${ }^{67}$ These outcomes involve development and acquisition of cognition, language, academic abilities, participation in school, vocational settings, broader society, and independence. Based on these guidelines and the literature reviewed above, the following time points are recommended for neurobehavioral follow-up. Changes or concerns encountered during evaluations should be communicated to the treatment team, particularly the spina bifida and neurosurgery teams, so that any needed interventions can be performed in a timely fashion.

\section{Age-Specific Recommendations Ages 0 to 1 Year}

Infants with MMC are typically monitored carefully for hydrocephalus during the 1st year. In conjunction with this, assessment of neurodevelopmental progress using standardized comprehensive infant development instruments (i.e., the Bayley Scales of Infant Development) can provide information about development and acquisition of abilities to inform medical/treatment planning and guide decision-making about parenting approaches and eligibility for early intervention. The child's motor, language, and cognitive functions throughout the 1st year are important metrics of medical status and developmental progress, and multiple evaluations during the 1st year (e.g., at 6 and 12 months) help provide information about the child's developmental trajectory.

\section{Ages 1 to 3 Years}

All children with MMC should be referred for early intervention (speech/language, occupational, and physical therapies) during this timeframe, particularly if there are changes in developmental status. Standardized assessments at ages 1-3 years are helpful in determining what supports children need to explore their environment (e.g., supportive seating) and participate in group activities, both of which are important for neurocognitive and psychosocial development. ${ }^{50}$ Use of standardized infant and toddler developmental instruments continues to be indicated as comprehensive measures are more sensitive to subtle weaknesses or changes in developmental progress, which may also signal a change in medical status.

\section{Ages 3 to 5 Years}

As children with MMC progress to preschool and kindergarten, an additional goal of neurodevelopmental/ neurobehavioral follow-up is determining readiness for preacademic and academic skill acquisition. Conducting a comprehensive neuropsychological evaluation around the time the child begins kindergarten is useful for guiding educational planning, including implementation of special education programs like an individualized education program or Section 504 plan.

\section{School Age}

As the child moves from early childhood into school 
age, evaluations should use a comprehensive battery of standardized neurobehavioral instruments assessing a broad range of neurocognitive/behavioral domains, as outlined above. Specific goals for school-age follow-up assessments change as expectations and demands change over the years. Scheduling neuropsychological evaluations around the time of major transitions in school is recommended. These time points all generally involve changes in demands for the child, such as the shift from learning to read to reading to learn around 3rd grade; the shift toward more autonomy and self-regulation that occurs during middle school; the continued increase in autonomy, independence, and self-management that occurs during high school; and finally the transition from high school to a career or post-secondary education in 12th grade. ${ }^{10}$

\section{Transitioning to Adulthood}

Managing the transition to young adulthood is critical for individuals with MMC, who may be less likely to pursue higher education, work full time, live independently, or develop romantic relationships than healthy peers. ${ }^{17}$ Predictors of success with these milestones include pathophysiology (no hydrocephalus, greater mobility), executive functioning abilities, family factors (SES, parental involvement), and logistical factors (financial stability, access to job training). ${ }^{17}$ When transitioning to adult healthcare, it is important for the healthcare team to provide direct referrals to adult providers, logistical support (vocational rehabilitation or transitioning health insurance), and active teaching to help develop the skills needed to transition. ${ }^{67}$ Neurocognitive monitoring during adulthood also remains important, particularly if changes in cognitive status occur (which may signal neurological changes). ${ }^{67}$

\section{Acknowledgments}

We would like to thank Eo Trueblood for his original artwork contribution.

\section{References}

1. Adzick NS: Fetal myelomeningocele: natural history, pathophysiology, and in-utero intervention. Semin Fetal Neonatal Med 15:9-14, 2010

2. Adzick NS, Thom EA, Spong CY, Brock JW III, Burrows PK, Johnson MP, et al: A randomized trial of prenatal versus postnatal repair of myelomeningocele. N Engl J Med 364:993-1004, 2011

3. Alimi Y, Iwanaga J, Oskouian RJ, Loukas M, Tubbs RS: Intelligence quotient in patients with myelomeningocele: a review. Cureus 10:e3137, 2018

4. Arrington CN, Ware AL, Ahmed Y, Kulesz PA, Dennis M, Fletcher JM: Are shunt revisions associated with IQ in congenital hydrocephalus? A meta-analysis. Neuropsychol Rev 26:329-339, 2016

5. Badell-Ribera A, Shulman K, Paddock N: The relationship of non-progressive hydrocephalus to intellectual functioning in children with spina bifida cystica. Pediatrics 37:787-793, 1966

6. Barkovich AJ, Raybaud C: Pediatric Neuroimaging, ed 5. Philadelphia: Lippincott Williams \& Wilkins, 2012

7. Barnes MA, Dennis M: Discourse after early-onset hydrocephalus: core deficits in children of average intelligence. Brain Lang 61:309-334, 1998

8. Barnes MA, Dennis M: Reading in children and adolescents after early onset hydrocephalus and in normally developing age peers: phonological analysis, word recognition, word comprehension, and passage comprehension skill. J Pediatr Psychol 17:445-465, 1992

9. Barnes MA, Faulkner HJ, Dennis M: Poor reading comprehension despite fast word decoding in children with hydrocephalus. Brain Lang 76:35-44, 2001

10. Baron IS: Neuropsychological Evaluation of the Child: Domains, Methods, and Case Studies, ed 2. New York: Oxford University Press, 2018

11. Bartoshesky LE, Haller J, Scott RM, Wojick C: Seizures in children with meningomyelocele. Am J Dis Child 139:400402, 1985

12. Bennett KA, Carroll MA, Shannon CN, Braun SA, Dabrowiak ME, Crum AK, et al: Reducing perinatal complications and preterm delivery for patients undergoing in utero closure of fetal myelomeningocele: further modifications to the multidisciplinary surgical technique. J Neurosurg Pediatr 14:108-114, 2014

13. Brewer VR, Fletcher JM, Hiscock M, Davidson KC: Attention processes in children with shunted hydrocephalus versus attention deficit-hyperactivity disorder. Neuropsychology 15:185-198, 2001

14. Burmeister R, Hannay HJ, Copeland K, Fletcher JM, Boudousquie A, Dennis M: Attention problems and executive functions in children with spina bifida and hydrocephalus. Child Neuropsychol 11:265-283, 2005

15. Chadduck W, Adametz J: Incidence of seizures in patients with myelomeningocele: a multifactorial analysis. Surg Neurol 30:281-285, 1988

16. Chan E, Leong P, Malouf R, Quigley MA: Long-term cognitive and school outcomes of late-preterm and early-term births: a systematic review. Child Care Health Dev 42:297312, 2016

17. Copp AJ, Adzick NS, Chitty LS, Fletcher JM, Holmbeck GN, Shaw GM: Spina bifida. Nat Rev Dis Primers 1:15007, 2015

18. Dennis M, Edelstein K, Copeland K, Frederick J, Francis DJ, Hetherington R, et al: Covert orienting to exogenous and endogenous cues in children with spina bifida. Neuropsychologia 43:976-987, 2005

19. Dennis M, Edelstein K, Copeland K, Frederick JA, Francis DJ, Hetherington R, et al: Space-based inhibition of return in children with spina bifida. Neuropsychology 19:456-465, 2005

20. Dennis M, Edelstein K, Hetherington R, Copeland K, Frederick J, Blaser SE, et al: Neurobiology of perceptual and motor timing in children with spina bifida in relation to cerebellar volume. Brain 127:1292-1301, 2004

21. Dennis M, Fletcher JM, Rogers T, Hetherington R, Francis DJ: Object-based and action-based visual perception in children with spina bifida and hydrocephalus. J Int Neuropsychol Soc 8:95-106, 2002

22. Dennis M, Jewell D, Drake J, Misakyan T, Spiegler B, Hetherington $\mathrm{R}$, et al: Prospective, declarative, and nondeclarative memory in young adults with spina bifida. J Int Neuropsychol Soc 13:312-323, 2007

23. Dennis M, Landry SH, Barnes M, Fletcher JM: A model of neurocognitive function in spina bifida over the life span. $\mathbf{J}$ Int Neuropsychol Soc 12:285-296, 2006

24. Dennis M, Salman MS, Juranek J, Fletcher JM: Cerebellar motor function in spina bifida meningomyelocele. Cerebellum 9:484-498, 2010

25. Devine KA, Holmbeck GN, Gayes L, Purnell JQ: Friendships of children and adolescents with spina bifida: social adjustment, social performance, and social skills. J Pediatr Psychol 37:220-231, 2012

26. Diamond A: Executive functions. Annu Rev Psychol 64:135-168, 2013

27. English LH, Barnes MA, Taylor HB, Landry SH: Math- 
ematical development in spina bifida. Dev Disabil Res Rev 15:28-34, 2009

28. Fletcher JM, Barnes M, Dennis M: Language development in children with spina bifida. Semin Pediatr Neurol 9:201-208, 2002

29. Fletcher JM, Bohan TP, Brandt ME, Kramer LA, Brookshire BL, Thorstad K, et al: Morphometric evaluation of the hydrocephalic brain: relationships with cognitive development. Childs Nerv Syst 12:192-199, 1996

30. Fletcher JM, Copeland K, Frederick JA, Blaser SE, Kramer LA, Northrup H, et al: Spinal lesion level in spina bifida: a source of neural and cognitive heterogeneity. J Neurosurg 102 (3 Suppl):268-279, 2005

31. Fletcher JM, Dennis M: Spina bifida and hydrocephalus, in Yeates KO, Ris MD, Taylor HB, Pennington BF (eds): Pediatric Neuropsychology: Research, Theory, and Practice, ed 2. New York: Guilford Press, 2009, pp 3-25

32. Friedman D, Holmbeck GN, Jandasek B, Zukerman J, Abad M: Parent functioning in families of preadolescents with spina bifida: longitudinal implications for child adjustment. J Fam Psychol 18:609-619, 2004

33. Hampton LE, Fletcher JM, Cirino P, Blaser S, Kramer LA, Dennis M: Neuropsychological profiles of children with aqueductal stenosis and spina bifida myelomeningocele. J Int Neuropsychol Soc 19:127-136, 2013

34. Hampton LE, Fletcher JM, Cirino PT, Blaser S, Kramer LA, Drake J, et al: Hydrocephalus status in spina bifida: an evaluation of variations in neuropsychological outcomes. J Neurosurg Pediatr 8:289-298, 2011

35. Hannay HJ, Dennis M, Kramer L, Blaser S, Fletcher JM: Partial agenesis of the corpus callosum in spina bifida meningomyelocele and potential compensatory mechanisms. J Clin Exp Neuropsychol 31:180-194, 2009

36. Heffelfinger AK, Koop JI, Fastenau PS, Brei TJ, Conant L, Katzenstein J, et al: The relationship of neuropsychological functioning to adaptation outcome in adolescents with spina bifida. J Int Neuropsychol Soc 14:793-804, 2008

37. Herweh C, Akbar M, Wengenroth M, Blatow M, Mair-Walther J, Rehbein N, et al: DTI of commissural fibers in patients with Chiari II-malformation. Neuroimage 44:306-311, 2009

38. Hetherington R, Dennis M, Barnes M, Drake J, Gentili F: Functional outcome in young adults with spina bifida and hydrocephalus. Childs Nerv Syst 22:117-124, 2006

39. Holmbeck GN, Coakley RM, Hommeyer JS, Shapera WE, Westhoven VC: Observed and perceived dyadic and systemic functioning in families of preadolescents with spina bifida. J Pediatr Psychol 27:177-189, 2002

40. Holmbeck GN, Devine KA: Psychosocial and family functioning in spina bifida. Dev Disabil Res Rev 16:40-46, 2010

41. Holmbeck GN, Johnson SZ, Wills KE, McKernon W, Rose B, Erklin S, et al: Observed and perceived parental overprotection in relation to psychosocial adjustment in preadolescents with a physical disability: the mediational role of behavioral autonomy. J Consult Clin Psychol 70:96-110, 2002

42. Holmbeck GN, Westhoven VC, Phillips WS, Bowers R, Gruse C, Nikolopoulos T, et al: A multimethod, multi-informant, and multidimensional perspective on psychosocial adjustment in preadolescents with spina bifida. J Consult Clin Psychol 71:782-796, 2003

43. Huber-Okrainec J, Blaser SE, Dennis M: Idiom comprehension deficits in relation to corpus callosum agenesis and hypoplasia in children with spina bifida meningomyelocele. Brain Lang 93:349-368, 2005

44. Juranek J, Dennis M, Cirino PT, El-Messidi L, Fletcher JM: The cerebellum in children with spina bifida and Chiari II malformation: quantitative volumetrics by region. Cerebellum 9:240-248, 2010

45. Kabagambe SK, Jensen GW, Chen YJ, Vanover MA, Farmer DL: Fetal surgery for myelomeningocele: a systematic review and meta-analysis of outcomes in fetoscopic versus open repair. Fetal Diagn Ther 43:161-174, 2018

46. Kelly NC, Ammerman RT, Rausch JR, Ris MD, Yeates KO, Oppenheimer SG, et al: Executive functioning and psychological adjustment in children and youth with spina bifida. Child Neuropsychol 18:417-431, 2012

47. Kulkarni AV, Riva-Cambrin J, Browd SR, Drake JM, Holubkov R, Kestle JR, et al: Endoscopic third ventriculostomy and choroid plexus cauterization in infants with hydrocephalus: a retrospective Hydrocephalus Clinical Research Network study. J Neurosurg Pediatr 14:224-229, 2014

48. Landry SH, Taylor HB, Swank PR, Barnes M, Juranek J: Longitudinal mediators of social problem solving in spina bifida and typical development. Rehabil Psychol 58:196-205, 2013

49. Lavrador JP, Ferreira V, Lourenço M, Alexandre I, Rocha M, Oliveira E, et al: White-matter commissures: a clinically focused anatomical review. Surg Radiol Anat 41:613-624, 2019

50. Lomax-Bream LE, Barnes M, Copeland K, Taylor HB, Landry SH: The impact of spina bifida on development across the first 3 years. Dev Neuropsychol 31:1-20, 2007

51. Loss N, OwenYeates K, Enrile BG: Attention in children with myelomeningocele. Child Neuropsychol 4:7-20, 1998

52. Mapstone TB, Rekate HL, Nulsen FE, Dixon MS Jr, Glaser N, Jaffe M: Relationship of CSF shunting and IQ in children with myelomeningocele: a retrospective analysis. Childs Brain 11:112-118, 1984

53. McLone DG, Dias MS: The Chiari II malformation: cause and impact. Childs Nerv Syst 19:540-550, 2003

54. McLone DG, Knepper PA: The cause of Chiari II malformation: a unified theory. Pediatr Neurosci 15:1-12, 1989

55. Miall RC, Reckess GZ, Imamizu H: The cerebellum coordinates eye and hand tracking movements. Nat Neurosci 4:638-644, 2001

56. Miller E, Widjaja E, Blaser S, Dennis M, Raybaud C: The old and the new: supratentorial MR findings in Chiari II malformation. Childs Nerv Syst 24:563-575, 2008

57. Naidich TP, Maravilla K, McLone DG: The Chiari II malformation, in McLaurin RL (ed): Proceedings of the Second Symposium on Spina Bifida. New York: Praeger, 1986, pp 164-173

58. Norkett W, McLone DG, Bowman R: Current management strategies of hydrocephalus in the child with open spina bifida. Top Spinal Cord Inj Rehabil 22:241-246, 2016

59. Petersen SE, Posner MI: The attention system of the human brain: 20 years after. Annu Rev Neurosci 35:73-89, 2012

60. Pinquart M, Shen Y: Anxiety in children and adolescents with chronic physical illnesses: a meta-analysis. Acta Paediatr 100:1069-1076, 2011

61. Pinquart M, Shen Y: Behavior problems in children and adolescents with chronic physical illness: a meta-analysis. J Pediatr Psychol 36:1003-1016, 2011

62. Ramat S, Leigh RJ, Zee DS, Optican LM: What clinical disorders tell us about the neural control of saccadic eye movements. Brain 130:10-35, 2007

63. Richards LJ, Plachez C, Ren T: Mechanisms regulating the development of the corpus callosum and its agenesis in mouse and human. Clin Genet 66:276-289, 2004

64. Rose BM, Holmbeck GN: Attention and executive functions in adolescents with spina bifida. J Pediatr Psychol 32:983994, 2007

65. Salman MS, Blaser SE, Sharpe JA, Dennis M: Cerebellar vermis morphology in children with spina bifida and Chiari type II malformation. Childs Nerv Syst 22:385-393, 2006

66. Sawin KJ, Bellin MH, Roux G, Buran C, Brei TJ, Fastenau PS: The experience of parenting an adolescent with spina bifida. Rehabil Nurs 28:173-185, 2003

67. Spina Bifida Association: Guidelines for the Care of People 
With Spina Bifida. Arlington, VA: Spina Bifida Association (https://www.spinabifidaassociation.org/guidelines/) [Accessed August 8, 2019]

68. Stoodley CJ, Limperopoulos C: Structure-function relationships in the developing cerebellum: evidence from early-life cerebellar injury and neurodevelopmental disorders. Semin Fetal Neonatal Med 21:356-364, 2016

69. Swartwout MD, Garnaat SL, Myszka KA, Fletcher JM, Dennis M: Associations of ethnicity and SES with IQ and achievement in spina bifida meningomyelocele. J Pediatr Psychol 35:927-936, 2010

70. Talamonti G, D'Aliberti G, Collice M: Myelomeningocele: long-term neurosurgical treatment and follow-up in 202 patients. J Neurosurg 107 (5 Suppl):368-386, 2007

71. Treble-Barna A, Juranek J, Stuebing KK, Cirino PT, Dennis M, Fletcher JM: Prospective and episodic memory in relation to hippocampal volume in adults with spina bifida myelomeningocele. Neuropsychology 29:92-101, 2015

72. Vinck A, Nijhuis-van der Sanden MW, Roeleveld NJ, Mullaart RA, Rotteveel JJ, Maassen BA: Motor profile and cognitive functioning in children with spina bifida. Eur J Paediatr Neurol 14:86-92, 2010

73. Weil AG, Westwick H, Wang S, Alotaibi NM, Elkaim L, Ibrahim GM, et al: Efficacy and safety of endoscopic third ventriculostomy and choroid plexus cauterization for infantile hydrocephalus: a systematic review and meta-analysis. Childs Nerv Syst 32:2119-2131, 2016

74. Williams VJ, Juranek J, Stuebing K, Cirino PT, Dennis M, Fletcher JM: Examination of frontal and parietal tectocorti- cal attention pathways in spina bifida meningomyelocele using probabilistic diffusion tractography. Brain Connect 3:512-522, 2013

75. Yeates KO, Enrile BG: Implicit and explicit memory in children with congenital and acquired brain disorder. Neuropsychology 19:618-628, 2005

\section{Disclosures}

The authors report no conflict of interest concerning the materials or methods used in this study or the findings specified in this paper.

\section{Author Contributions}

Conception and design: Schreiber, Foss, Heuer. Acquisition of data: Schreiber, Foss. Analysis and interpretation of data: all authors. Drafting the article: all authors. Critically revising the article: all authors. Reviewed submitted version of manuscript: all authors. Approved the final version of the manuscript on behalf of all authors: Schreiber. Administrative/technical/material support: Foss, Heuer.

\section{Correspondence}

Jane E. Schreiber: Children's Hospital of Philadelphia, PA. schreiberj@email.chop.edu. 